\title{
Can reactive iron preserve organic carbon during permafrost collapse?
}

A. KAPPLER ${ }^{1}$, M.S. PATZNER ${ }^{1}$, M. LOGAN $^{2}$, H. JOSS ${ }^{1}$, C.

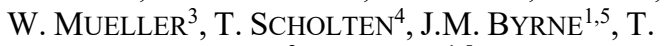

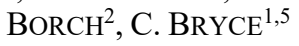

${ }^{1}$ Geomicrobiology, University of Tübingen, Germany; ${ }^{2}$ Soil \& Crop Sciences, Colorado State University, Fort Collins, US; ${ }^{3}$ Chair of Soil Science, Technical

University Munich, Freising, Germany; ${ }^{4}$ Soil Science and Geomorphology, University of Tübingen, Germany; ${ }^{5}$ School of Earth Sciences, University of Bristol, Bristol, UK.

(andreas.kappler@uni-tuebingen.de)

Binding of organic carbon by iron minerals can prevent carbon mobilization and degradation in marine sediments, tropical and upland soils, and wetlands. This "rusty carbon sink" was also suggested to protect carbon in soils overlying intact permafrost. Previous studies (1) showed that approximately $20 \%$ of the total organic carbon was bound to reactive iron in Tibetan permafrost soils. Our own analyses of soils overlying intact permafrost in both Barrow (Alaska) and in Abisko (Sweden) also revealed up to 25 and $20 \%$ of the total organic carbon bound to reactive iron, respectively. However, the extent to which iron-bound carbon will be mobilized during permafrost thaw is unknown. To assess the fate of these $\mathrm{Fe}-\mathrm{C}$ associations during permafrost collapse, we have followed the dynamic interactions between iron and carbon along a thaw gradient at Stordalen mire (Sweden), where wetlands are expanding rapidly due to permafrost retreat. Our results showed that the rusty carbon sink is lost during thaw due to more reduced conditions which favour microbial $\mathrm{Fe}(\mathrm{III})$ mineral reduction and dissolution. This leads to high dissolved $\mathrm{Fe}(\mathrm{II})(2.9 \pm 0.4 \mathrm{mM})$ and dissolved organic carbon $(480.1 \pm 34.1 \mathrm{mg} / \mathrm{L})$ in the porewater at the transition of desiccating palsa to waterlogged bog. Along the thaw gradient, $100 \%$ of the organic carbon bound to reactive iron is lost. Additionally, by combining FT-ICR-MS and greenhouse gas analysis both in the field and in laboratory microcosm experiments, we have determined the fate of the mobilized organic carbon directly after permafrost collapse and during wetland expansion.

(1) Mu, C. C., T. J. Zhang, Q. Zhao, H. Guo, W. Zhong, H. Su, and Q. B. Wu (2016), Soil organic carbon stabilization by iron in permafrost regions of the Qinghai-Tibet Plateau, Geophys. Res. Lett., 43, 10,286-10,294, doi:10.1002/ 2016GL070071. 